\title{
Increased ABCA1 activity protects against atherosclerosis
}

\author{
Roshni R. Singaraja, ${ }^{1,2}$ Catherine Fievet, ${ }^{3}$ Graciela Castro, ${ }^{3}$ Erick R. James, ${ }^{2}$ \\ Nathalie Hennuyer, ${ }^{3}$ Susanne M. Clee, ${ }^{1}$ Nagat Bissada, ${ }^{1}$ Jonathan C. Choy, ${ }^{4}$ \\ Jean-Charles Fruchart, ${ }^{3}$ Bruce M. McManus, ${ }^{4}$ Bart Staels, ${ }^{3}$ and Michael R. Hayden ${ }^{1}$ \\ ${ }^{1}$ Centre for Molecular Medicine and Therapeutics, Children's and Women's Hospital, University of British Columbia, \\ Vancouver, British Columbia, Canada \\ ${ }^{2}$ Xenon Genetics Inc., Burnaby, British Columbia, Canada \\ ${ }^{3}$ Institut Pasteur de Lille, UMR545 Inserm and Faculté de Pharmacie, Université de Lille II, Cedex, France \\ ${ }^{4}$ The iCAPTURE Centre, and Department of Pathology and Laboratory Medicine, St. Paul's Hospital- \\ University of British Columbia, Vancouver, British Columbia, Canada
}

The $\mathrm{ABC}$ transporter $\mathrm{ABCA} 1$ plays a key role in the first steps of the reverse cholesterol transport pathway by mediating lipid efflux from macrophages. Previously, it was demonstrated that human ABCA1 overexpression in vivo in transgenic mice results in a mild elevation of plasma HDL levels and increased efflux of cholesterol from macrophages. In this study, we determined the effect of overexpression of $\mathrm{ABCA} 1$ on atherosclerosis development. Human $A B C A 1$ transgenic mice $\left(\mathrm{BAC}^{+}\right)$were crossed with $A p o E^{-/-}$mice, a strain that spontaneously develop atherosclerotic lesions. $B A C^{+} A p o E^{-/-}$ mice developed dramatically smaller, less-complex lesions as compared with their $A p o E^{-/-}$counterparts. In addition, there was increased efflux of cholesterol from macrophages isolated from the $B A C^{+} A p o E^{-/-}$mice. Although the increase in plasma HDL cholesterol levels was small, HDL particles from $B A C^{+} A p o E^{-/-}$mice were significantly better acceptors of cholesterol. Lipid analysis of HDL particles from $B A C^{+} A p o E^{-/-}$mice revealed an increase in phospholipid levels, which was correlated significantly with their ability to enhance cholesterol efflux. We conclude that raising ABCA1 activity in vivo results in significant protection against atherosclerosis.

This article was published online in advance of the print edition. The date of publication is available from the JCI website, http://www.jci.org. J. Clin. Invest. 110:35-42 (2002). doi:10.1172/JCI200215748.

\section{Introduction}

The inverse relationship between serum concentration of HDL cholesterol (HDL-C) and ApoA-I with coronary heart disease is well-established (1). The ability to promote reverse cholesterol transport is accepted as one important mechanism by which HDL can protect against atherosclerosis (2). Reverse cholesterol transport is the process by which cholesterol is removed from extrahepatic tissues and returned to the liver for conversion into bile acids and excretion into bile. Inhibition of the oxidative modification of LDL (3) and downregulation of the cytokine-induced expression of adhesion molecules in endothelial cells

Received for publication April 22, 2002, and accepted in revised form May 21, 2002

Address correspondence to: Michael R. Hayden, Centre for Molecular Medicine and Therapeutics, 950 West 28th Avenue, Vancouver, British Columbia V5Z 4H4, Canada.

Phone: (604) 875-3535; Fax: (604) 875-3819;

E-mail: mrh@cmmt.ubc.ca.

Conflict of interest: This study was partly supported by

XenonGenetics Inc. Michael Hayden is the chair of the scientific advisory board of Xenon Genetics Inc.

Nonstandard abbreviations used: HDL cholesterol (HDL-C); adenosine triphosphate-binding cassette transporter A1

(ABCA1); bacterial artificial chromosome (BAC); oil red O

(ORO); acyl-CoA:cholesterol O-acyltransferase (ACAT); coronary artery disease (CAD).
(4) are other mechanisms proposed to explain the atheroprotective actions of HDL.

The presence of macrophage-derived foam cells is one of the characteristic features of the early stages of atherosclerotic lesion formation $(5,6)$. Efficient cholesterol efflux from macrophages is critical for the prevention of foam cell formation and subsequent protection against atherosclerosis. The first crucial step in the reverse cholesterol transport pathway is the movement of excess cellular cholesterol and phospholipid from cell membranes to nascent HDL particles $(7,8)$. The adenosine triphosphate-binding cassette transporter A1 (ABCA1) plays a key role in this process, although the biochemical mechanisms involved remain to be elucidated. One model proposes that rather than interacting directly with cholesterol, ABCA1 facilitates the translocation of phospholipids to free ApoA-I at the plasma membrane. The phospholipid-ApoA-I complexes thus formed may subsequently stimulate the efflux of cholesterol in a secondary fashion $(9,10)$. Alternatively, ABCA1 may act as a cholesterol/phospholipid flippase at the plasma membrane, since it stimulates phospholipid and cholesterol efflux to ApoA-I $(11,12)$. Disruption in ABCA1 function due to mutations in the $A B C A 1$ gene causes Tangier disease and familial hypoalphalipoproteinemia, which are characterized by low to absent HDL levels and an 
increased deposition of cholesteryl esters in several tissues and cells, most notably in macrophages (13). A 50\% reduction in ABCA1 activity is associated with a significant decrease in plasma HDL-C levels (14-16).

To study the role of ABCA 1 in HDL metabolism and atherosclerosis, we have developed human ABCA1 overexpressing bacterial artificial chromosome (BAC) transgenic mice that show increased total plasma cholesterol and HDL-C levels and increased ApoA-I and ApoA-II levels (17), associated with increased cholesterol efflux from macrophages. We hypothesized that increasing $\mathrm{ABCA} 1$ activity would be associated with reduced atherosclerotic lesion formation.

$A p o E^{-/-}$mice have been used extensively to study atherogenesis. These mice spontaneously develop severe atherosclerosis, with complex lesions that include a fibrous cap in mice as young as 15 weeks of age. Because of its validation and acceptance as a model to study factors influencing atherogenesis, we chose to test the effect of ABCA1 overexpression on atherosclerosis development, macrophage cholesterol efflux, and HDL composition in this model.

\section{Methods}

Generation of $A B C A 1 B A C^{+} A p o E^{-/-}$mice. The generation of the $A B C A 1 \mathrm{BAC}$ transgenic mice has been described previously (17). $A B C A 1 \mathrm{BAC}$ transgenic mice hemizygous for the human $A B C A 1$ gene and backcrossed to $\mathrm{C} 57 \mathrm{BL} / 6 \mathrm{~J}(\mathrm{~N} 3)$ were crossed to $A p o E^{-/-}$mice on a pure C57BL/6 background (C57BL/6J ApoEtm1Unc). The resulting $B A C^{+} A p o E^{+/-}$mice were backcrossed once more to the $A p o E^{-/-}$mice, and the $B A C^{+} A p o E^{-/-}$offspring were then backcrossed again to $A p o E^{-/-}$mice, generating $B A C^{+} A p o E^{-/-}$and $B A C-A p o E^{-/-}$(henceforth called $\mathrm{ApoE}^{-/-}$) control littermates that were backcrossed to the N6 generation (98.4\%) on the C57BL/6J background. All experiments were performed with the approval of the Animal Care Committee of the University of British Columbia. Histological manipulations of aortas. For the analysis of aortic lesions, 12 -week-old $B A C^{+} A p o E^{-/-}$and $A p o E^{-/-}$littermate controls kept on a chow diet were fasted for 4 hours, followed by injection of $400 \mu \mathrm{l}$ of $0.02 \mathrm{~g} / \mathrm{ml}$ Avertin (Sigma-Aldrich, St. Louis, Missouri, USA). The chow diet was a 1:1 mix of PicoLab Mouse Diet 20 and PicoLab Rodent Diet 20, containing $9 \%$ and $4.5 \%$ fat, respectively. Tissues were harvested for RNA and protein analysis. Mice were perfused transcardially with $4 \%$ paraformaldehyde (Fisher Scientific Co., Nepean, Ontario, Canada), and the hearts with attached aortas were isolated. Tissues were embedded in Tissue-Tek OCT (Sakura Finetek USA Inc., Torrance, California, USA) media in a plastic mold, frozen, and sixteen $10-\mu \mathrm{m} \mathrm{sec}-$ tions were cut. For oil red O (ORO) staining, the sections were rinsed in water and isopropanol and stained in $0.25 \%$ ORO for 20 minutes, followed by an isopropanol rinse. Sections were counterstained in Gill's hematoxylin for 1 minute and mounted. For Movat's pentachrome staining, sections were hydrated, stained in $1 \%$ Alcian blue for 30 minutes, and rinsed in 1\% acetic acid. Sec- tions were then post-fixed in formol-sublimate fixative overnight, rinsed, and treated with Lugol's iodine for 4 minutes. Sections were treated with $5 \%$ sodium thiosulfate, stained in Verhoeff's hematoxylin, and differentiated in $2 \%$ ferric chloride. Sections were air dried, stained in $1.5 \%$ saffron for 1 minute, dehydrated in $100 \%$ ethanol, and mounted. Transverse sections were obtained from the apex of the heart moving toward the aortic region, with sections beginning at the point where all three aortic valve cusps became clearly visible. Every fourth section was placed on a slide for ORO staining of neutral lipid and counterstained with hematoxylin, such that each slide had four sections $40 \mu \mathrm{m}$ apart, as previously described (18). Sections adjacent to those stained with ORO were stained with Movat's pentachrome for the identification of elastin, collagen, glycosaminoglycans, smooth muscle cells, and foam cells.

Lesion assessment. Assessment of lesions was performed as described previously (18). Lesion areas were photographed using an Axioskop2 (Carl Zeiss Canada Ltd., Toronto, Ontario, Canada) microscope, with a SPOT (Diagnostic Instruments Inc., Sterling Heights, Michigan, USA) camera, and Northern Eclipse software (Empix Imaging Inc., Mississauga, Ontario, Canada) was used for quantitation of ORO-positive areas within the lesion sites. The total ORO staining of four sections within the sinuses of Valsalva were averaged to provide the lesion area for each mouse.

Protein analysis. To ensure that the tissue distribution of ABCA1 protein had not been altered in the absence of the ApoE gene, we isolated proteins from various tissues and subjected them to Western blot analysis. Tissue extracts were prepared as previously described (17). Total protein was transferred to a PVDF membrane (Millipore Corp., Bedford, Massachusetts, USA), and Western immunoblotting was performed with a primary anti-ABCA1 $\mathrm{mAb}$ raised against the second nucleotide-binding domain of human ABCA1 (19). Blots were probed with anti-GAPDH (Sigma-Aldrich) to ensure equal protein loading.

Expression of human-specific ABCA1 transcript. To definitively determine if the human $\mathrm{BAC}$ is expressed in the mice, we performed human $A B C A 1$-specific RT-PCR analysis. PCR primers and conditions were as described previously (17).

Efflux of ${ }^{3} \mathrm{H}$-cholesterol from primary macrophages. Mice were injected with $2 \mathrm{ml}$ of $3 \%$ thioglycollate broth. Three days later, peritoneal macrophages were isolated and plated at a density of $5 \times 10^{5}$ cells $/ \mathrm{ml}$ into each of eight wells of a 24-well plate. $\left[{ }^{3} \mathrm{H}\right]$-cholesterol $(2 \mu \mathrm{Ci} / \mathrm{ml})($ Perkin Elmer Life Sciences Inc., Boston, Massachusetts, USA) and $50 \mu \mathrm{g} / \mathrm{ml}$ acylated LDL (INTRACEL Corp., Frederick, Maryland, USA) were preincubated at $37^{\circ} \mathrm{C}$ for 30 minutes and subsequently added to DMEM containing $1 \% \mathrm{FBS}$, penicillin/streptomycin, L-glutamine, and $1 \mu \mathrm{M}$ acyl-CoA:cholesterol $O$-acyltransferase (ACAT) inhibitor (CI 976; a kind gift from Minghan Wang, Pfizer Global Research, Ann Arbor, Michigan, USA). The addition of the ACAT inhibitor decreases the levels of cholesterol 
esterification in macrophages and therefore facilitates free cholesterol efflux out of the cells (20). Cells were incubated in this medium $(300 \mu \mathrm{l})$ for another 24 hours and equilibrated by incubation for another 24 hours. The media were then changed to the equilibration media either with or without $20 \mu \mathrm{g} / \mathrm{ml}$ ApoA-I (CalbiochemNovabiochem Corp., San Diego, California, USA), 4 $\mu \mathrm{g} / \mathrm{ml}$ 22(R)-hydroxy cholesterol (Steraloids Inc., Newport, Rhode Island, USA), and $10 \mu \mathrm{M} 9$ (cis)-retinoic acid (Sigma-Aldrich). Efflux was quantified using a Microbeta plate reader (Perkin Elmer Lifesciences Inc.), and the data were calculated by dividing the counts in the media by the total counts of the media and the cells. Efflux values are an average of three wells per experiment with each experiment repeated four times.

Lipid analysis. Serum and lipoprotein lipid (cholesterol, triglycerides) concentrations were determined by enzymatic assays using commercially available reagents (Boehringer Mannheim GmbH, Mannheim, Germany). Serum HDL-C levels were determined after precipitation of ApoB-containing lipoproteins with phosphotungstic acid/mg (Roche Diagnostics GmbH, Mannheim, Germany). Serum levels of ApoA-I, ApoA-II, ApoB, and ApoC-III were measured by an immunonephelemetric assay using specific mouse polyclonal Ab's as described previously (21).
HDL lipoprotein $($ density $=1.063-1.21 \mathrm{~g} / \mathrm{ml}$ ) and lipid-free protein (density $>1.21 \mathrm{~g} / \mathrm{ml}$ ) fractions were isolated from serum by sequential ultracentrifugation (22). The HDL fraction was assayed for its protein (23) and lipid (cholesterol, triglyceride, and phospholipid) content. The Apo lipoprotein composition of ultracentrifugally isolated fractions was analyzed by PAGE under denaturing $(0.1 \%$ SDS $)$ and nonreducing conditions on ready-to-use gels (4-20\%; Novex, San Diego, California, USA) as described (24). Gels were stained with Coomassie brilliant blue R-250 or transferred to nitrocellulose membranes. Replicates were used for immunochemical detection of murine ApoA-I and ApoA-IV using specific Ab's and images scanned using a densitometer (GS-300 scanning densitometer; Hoefer Scientific Instruments, San Francisco, California, USA).

Cholesterol efflux in response to serum lipid fractions. The capacity of serum lipid fractions to stimulate cellular cholesterol efflux was determined using Fu5AH rat hepatoma cells, following the procedure described by de la Llera Moya et al. (25). Fu5AH cells $(50,000)$ were plated, after which cellular cholesterol was labeled with ${ }^{3} \mathrm{H}$-cholesterol (NEN, Dupont de Nemurs, Paris, France) $(1 \mu \mathrm{Ci} /$ well). The cells were subsequently washed with PBS and incubated with either a 5\% dilution of whole mouse serum or $50 \mu \mathrm{g} / \mathrm{ml} \mathrm{HDL}$ (density between 1.063

\section{a}

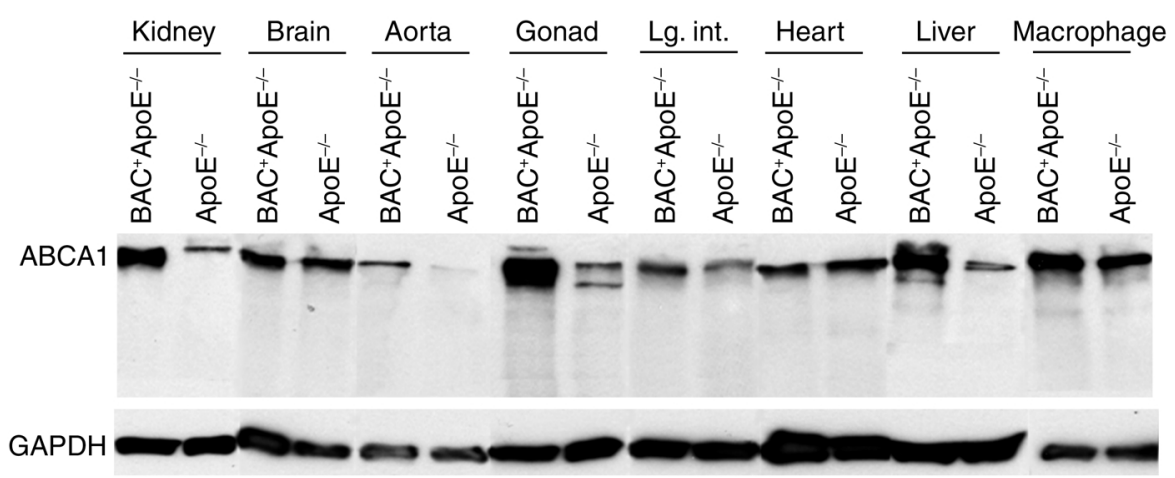

b

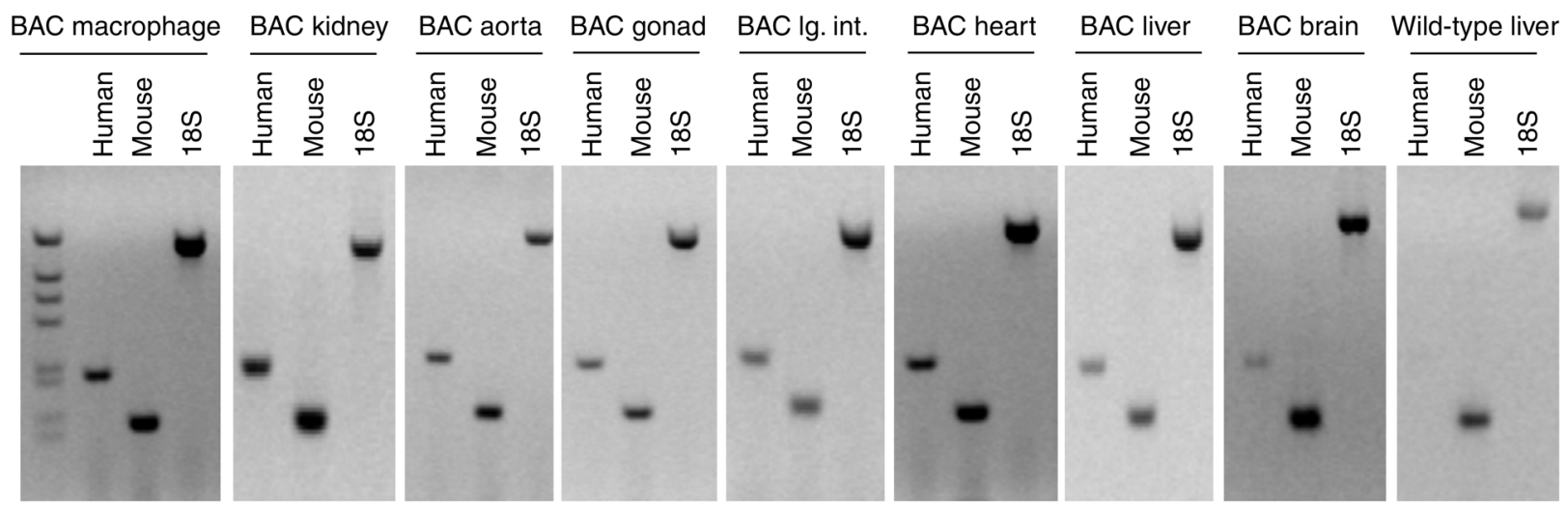

Figure 1

Expression of $A B C A 1$ in $B A C^{+} A p o E^{-/-}$mice. Increased $A B C A 1$ protein was detected in the liver, kidney, brain, aorta, gonad, large intestine (lg. int.), and in peritoneal macrophage cells isolated from the $B A C^{+} A p o E^{-/-}$mice (a). An anti-ABCA1 mAb raised against the second nucleotidebinding domain was used (top panel) to detect ABCA1. To ensure equal protein loading, the Western blots were probed with anti-GAPDH $\mathrm{Ab}$ (lower panel). (b) Human-specific ABCA1 transcript was detected in all tissues tested using RT-PCR. For each tissue, lane 1 is human specific, lane 2 is mouse specific, and lane 3 is an $18 \mathrm{~S}$ control. The last panel is from a control mouse and contains no human transcript. 


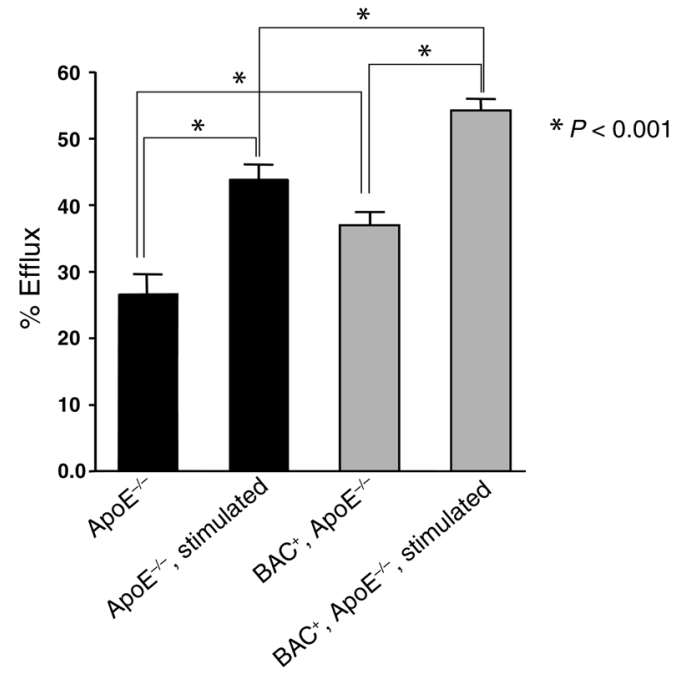

Figure 2

Analysis of efflux levels in primary macrophages from $B A C^{+} A p o E^{-/-}$ mice. Primary peritoneal macrophage cultures were established from the $B A C^{+} A p o E^{-/-}$and control mice as described $(n=4)(17)$. A $38.4 \%$ increase $(P<0.001)$ in efflux in the $B A C^{+} A p o E^{-/-}$macrophages is evident when compared with the $A p o E^{-/-}$littermates. Upon stimulation of the cultures with 9(cis)-retinoic acid and 22(R)-hydroxy cholesterol, there was a $23.7 \%$ increase $(P<0.001)$ in cholesterol efflux between $B A C^{+} A p o E^{-/-}$versus control littermates. There was a further $46.8 \%$ increase $(P<0.001)$ in efflux in the $B A C^{+} A p o E^{-/-}$macrophages after stimulation with 9 (cis)-retinoic acid and 22(R)-hydroxy cholesterol when compared with unstimulated cells.

and $1.21 \mathrm{~g} / \mathrm{ml}$ ) isolated from $B A C^{+} A p o E^{-/-}$and $A p o E^{-/-}$ control littermates. The medium was removed and centrifuged and the cell monolayer washed and harvested. Radioactivity was then measured in both medium and cells, and the percentage of cholesterol efflux was calculated. Efflux values are averages of three to four determinations, each performed in triplicate.

Statistical analysis. Statistical analysis was performed using GraphPad Prism (GraphPad Software for Science Inc., San Diego, California, USA) version 2.0. The twotailed unpaired Student $t$ test was used for all analyses, with a $P$ value for significance set at 0.05 .

\section{Results}

Increased $A B C A 1$ protein levels in tissues of $B A C^{+} A p o E^{-/-}$mice. Increased $A B C A 1$ protein levels were observed in the liver, kidney, brain, aorta, gonads, and large intestine of the $A B C A 1 B A C^{+} A p o E^{-/-}$mice, similar to data previously shown (17) for the $A B C A 1 \mathrm{BAC}^{+}$transgenic mice (Figure 1a). ABCA1 protein levels were also increased in peritoneal macrophages from the $B A C^{+} A p o E^{-/-}$mice compared with $A p o E^{-/}$littermates, as previously shown for the $\mathrm{BAC}^{+}$mice (17). All protein levels were assessed by densitometry with GAPDH used as a control.

Human ABCA1 transcript is expressed in tissues. Using human-specific RT-PCR, human transcripts were detected in the liver, kidney, brain, aorta, gonads, large intestine, brain, heart, and macrophages of the transgenic mice (Figure 1b).
$A B C A 1 B A C^{+} A p o E^{-/-}$mice show increased cholesterol efflux from peritoneal macrophages. To examine whether the increased $\mathrm{ABCA} 1$ in the $B A C^{+} A p o E^{-/-}$mice was functional in the absence of ApoE gene expression, cholesterol efflux assays were performed on peritoneal macrophages. As shown for macrophages and fibroblasts isolated from the $\mathrm{ABCA} 1 \mathrm{BAC}^{+}$transgenic mice (17), macrophages isolated from $B A C^{+} A p o E^{-1-}$ mice also showed increased efflux of cholesterol to ApoA-I compared with cells isolated from $A p o E^{-/-}$control littermates $(n=4, P<0.001)$ (Figure 2). This efflux was further increased upon stimulation of the cells with 22(R)-hydroxy cholesterol and 9(cis)-retinoic acid, indicating that even in the absence of the ApoE gene the ABCA1 transgene is induced by specific activators of the LXR/RXR pathway, as previously shown (17). These data clearly show that normal ABCA1 activity is independent of ApoE expression within cells.

$A B C A 1 B A C^{+} A p o E^{-/-}$mice have mildly increased $H D L-C l e v-$ els. A small increase in HDL-C levels was observed in the $B A C^{+} A p o E^{-/-}$mice when compared with the littermates without the BAC transgene $(0.25 \pm 0.07 \mathrm{~g} / \mathrm{l}), n=13$, vs. $0.20 \pm 0.03 \mathrm{~g} / \mathrm{l}$ ), $n=11 ; P=0.04$ (Table 1). $B A C^{+} A p o E^{-/-}$ mice displayed slightly elevated concentrations of serum total cholesterol when compared with $A p o E^{-/-}$littermates $(P=0.04)$, as reflected by the increase in both HDL-C levels stated and non-HDL cholesterol $(P=0.05)$ (Table 1). These data were confirmed by fast-protein liquid chromatography analysis (data not shown).

Triglycerides were not influenced by the transgene, whereas ApoB $(P=0.03)$ and ApoC-III $(P=0.05)$ concentrations were slightly increased in the $B A C^{+} A p o E^{-/-}$ mice. No significant differences in the plasma levels of ApoA-I and ApoA-II (Table 1) between the $B A C^{+} A p o E^{-/-}$ mice and the control littermates were seen (confirmed by SDS-PAGE analysis, data not shown).

$B A C^{+} A p o E^{-1-}$ mice show a significant decrease in atherosclerotic lesions. ApoE $E^{-1-}$ mice develop detectable lesions in the aortic sinus valve as early as 10 weeks of age (5). These lesions enlarge in size and progress to the aortic arch as the mice age. Aortas from 12-week-old mice were harvested, the aortic valve region sectioned, and the ORO positive-stained areas measured (Figure 3a). A marked (2.7-fold) decrease in the lesion area was

\section{Table 1}

Lipid profiles of $\mathrm{ABCA} 1 \mathrm{BAC}^{+} A p o E^{-/-}$and $A p o E^{-/-}$control mice

\begin{tabular}{lccc}
\hline & $\begin{array}{c}B A C^{+} A p o E^{-/-} \\
(n=13)\end{array}$ & $\begin{array}{c}A p o E^{-/-} \\
(n=11)\end{array}$ & $P$ value \\
& $7.49 \pm 1.25$ & $6.52 \pm 0.83$ & 0.04 \\
TC $(\mathrm{g} / \mathrm{l})$ & $7.24 \pm 1.23$ & $6.32 \pm 0.83$ & 0.05 \\
Non HDL-C $(\mathrm{g} / \mathrm{l})$ & $0.25 \pm 0.07$ & $0.20 \pm 0.03$ & 0.04 \\
HDL-C $(\mathrm{g} / \mathrm{l})$ & $1.37 \pm 0.39$ & $1.18 \pm 0.36$ & 0.23 \\
TG $(\mathrm{g} / \mathrm{l})$ & $0.17 \pm 0.03$ & $0.16 \pm 0.03$ & 0.42 \\
ApoA I $(\mathrm{g} / \mathrm{l})$ & $0.14 \pm 0.04$ & $0.12 \pm 0.02$ & 0.15 \\
ApoA II $(\mathrm{g} / \mathrm{l})$ & $0.65 \pm 0.13$ & $0.55 \pm 0.06$ & 0.03 \\
ApoB $(\mathrm{g} / \mathrm{I})$ & $0.67 \pm 0.16$ & $0.56 \pm 0.08$ & 0.05 \\
ApoC III $(\mathrm{g} / \mathrm{l})$ & & &
\end{tabular}

TC, total cholesterol; TG, triglycerides. 
observed in the $B A C^{+} A p o E^{-/-}$mice when compared with $A p o E^{-/}$littermates $\left(27.9 \mathrm{~mm}^{2}\right.$ vs. $\left.74.1 \mathrm{~mm}^{2} ; P<0.0001\right)$ (Figures 3 , a and b).

Moderately advanced atherosclerotic intimal lesions in the noncoronary and coronary sinuses of the $\mathrm{ApoE}^{-/}$ mice (Figure 3d) were evident, limited primarily to the root of attachment of the valve cusps. The lesions in the aortic sinuses in the $A p o E^{-/-}$mice were more extensive than in the sinuses of $B A C^{+} A p o E^{-/-}$mice, often being confluent from commissure to commissure. Advanced noncoronary aortic sinus lesions were enriched with foam cells, had an apparently intact overlying endothelium, and contained several mesenchymal cells within the deep intimal matrix. There were no observable atherosclerotic lesions in the coronary arteries. Prominent intimal ORO positivity was seen in all aortic sinuses of $A p o E^{-/-}$mice. However, much more lipid deposition, in the form of both micro- and macrodroplets, was

\section{a}

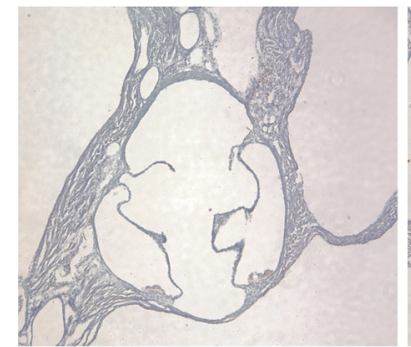

$\mathrm{BAC}^{+}, \mathrm{Apo}^{-1-}$

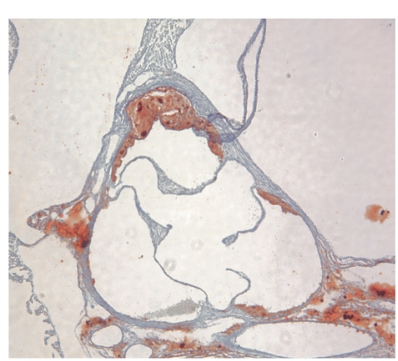

$\mathrm{ApoE}^{-1-}$ b

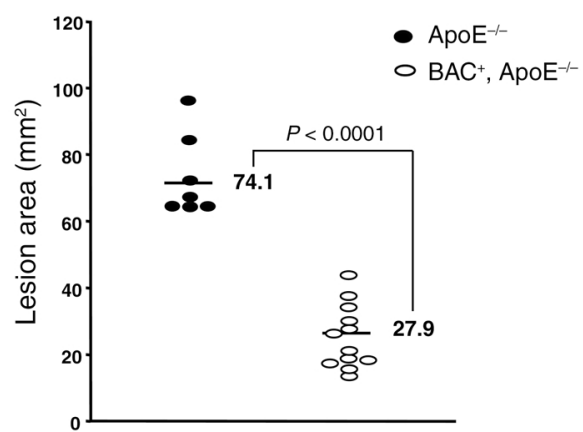

observed in the noncoronary sinuses than in the coronary sinuses. In general, ORO staining was localized to foam cells. In the aortic sinuses from $A p o E^{-1-}$ mice there was extensive deep intimal matrix deposition (observed as a sea-green color) toward the commissures. Also, extracellular cholesterol clefts were observed in these lesions, along with thinning of the walls of the sinuses of Valsalva. The beginning of a fibrous cap was observed in the more advanced lesions (Figure $3 \mathrm{~h}$ ).

In contrast to the $A p o E^{-/-}$mice, there was markedly reduced atherosclerosis in the aortic sinuses of $B A C^{+} A p o E^{-/-}$mice, a difference easily seen by the naked eye. Occasional small, early, focal pericommissural foam cell-rich lesions in some noncoronary sinuses and many small aggregates of foam cells in the intima of both noncoronary and coronary sinuses were evident. As in the $A p o E^{-/-}$mice, there was no involvement of the coronary arteries. ORO staining was markedly less in aortic

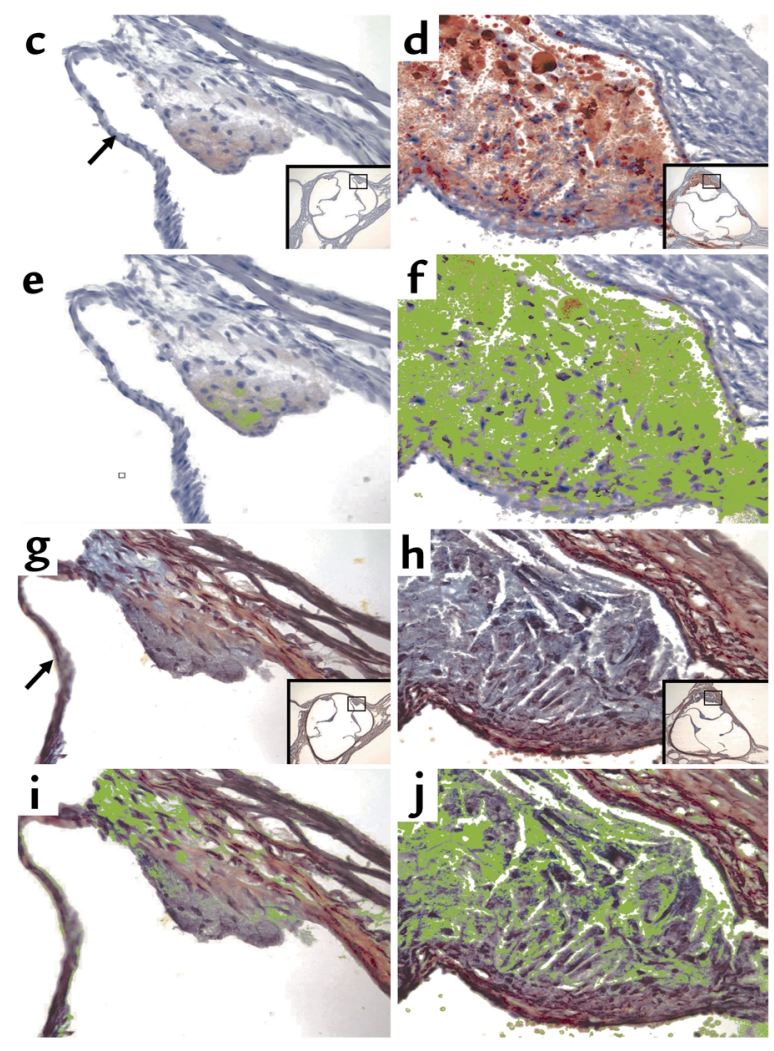

\section{Figure 3}

Assessment of lesions in $B A C^{+} A p o E^{-/-}$mice. (a) Lesions in aortic roots of $B A C^{+} A p o E^{-/-}$mice (left) and $A p o E^{-/-}$(right $)$mice $(\times 5)$ were stained with ORO to detect the accumulation of lipids. $B A C^{+} A p o E^{-/-}$mice showed 2.7 times decrease in lesion size compared with the $A p o E^{-/-}$mice (b). ORO-stained sections were used for the assessment of lesions (c and $\mathbf{d})(\times 24$; inset $\times 4$, transversely sectioned aortic root). Lesions were markedly smaller and less well-developed in $B A C^{+} A p o E^{-/-}$mice as compared with $A p o E^{-/-}$mice. Markedly less ORO positivity was seen in foam cells from $B A C^{+} A p o E^{-/-}$mice as compared with $A p o E^{-/-}$mice. A color overlay based on hue, saturation, and intensity further shows a dramatic decrease in ORO positivity (green color) in lesions from $B A C^{+} A p o E^{-/-}$mice (e), compared with $A p o E^{-/-}$mice (f) ( $\left.\times 24\right)$. For the assessment of lesion complexity in $B A C^{+} A p o E^{-/-}$mice, lesions in aortic roots of $B A C^{+} A p o E^{-/-}$mice $(\mathbf{g})$ and $A p o E^{-/-}$mice (h) were stained with Movat's pentachrome to visualize extracellular matrix deposition within the lesions $(\times 24$; inset $\times 4$, transversely sectioned aortic root). Small amounts of matrix rich in proteoglycans, especially versican (reflected here as sea-green color corresponding to glycosaminoglycan content), is observed in lesions from $B A C^{+} A p o E^{-/-}$mice, particularly near the noduli Arantii. Furthermore, these early lesions have only a very faint intimal positivity. However, in lesions of the $A p o E^{-/-}$mice, glycosaminoglycan is observed in deep intimal areas of the lesions underlying the foam cell-rich regions. Also, extracellular matrix deposition is observed interwoven with extracellular cholesterol clefts and near the noduli Arantii. A color overlay reflecting extracellular matrix based on hue, saturation, and intensity shows differential localization of these components (green color) in $B A C^{+} A p o E^{-/-}(\mathbf{i})$ and $A p o E^{-/-}$mice $(\mathbf{j})(\times 24)$. An aortic valve cusp is denoted in $\mathbf{g}($ arrow). 
Table 2

Efflux to HDL and serum isolated from $\mathrm{ABCA} 1 B A C^{+} A p o E^{-/-}$and $A p o E^{-/-}$mice

\begin{tabular}{llcc}
\hline $\mathrm{HDL}$ & \multicolumn{2}{c}{ Fu5AH $(n=4)$} & \\
$A p o E^{-/-}$ & $B A C^{+} A p o E^{-/-}$ & $P$ value & $\%$ Increase \\
$9.97 \pm 0.73$ & $13.27 \pm 0.73$ & 0.0007 & 33.10 \\
Serum & \multicolumn{2}{c}{ Fu5AH $(n=4)$} & \\
$A p o E^{-/-}$ & $B A C^{+} A p o E^{-/-}$ & $P$ value & $\%$ Increase \\
$16.75 \pm 0.08$ & $18.32 \pm 0.32$ & $<0.0001$ & 9.37 \\
\hline
\end{tabular}

sinuses of $B A C^{+} A P o E^{-/-}$mice (Figure $3 c$ ). There was diffuse ORO positivity in foam cells in areas around the commissures. In Movat's pentachrome-stained sections from the $B A C^{+} A p o E^{-1-}$ mice, there was only slight matrix enrichment in the noduli Arantii (Figure 3g). Furthermore, only limited thinning of the sinus walls was observed, with no fibrous cap formation.

$H D L$ and serum from $B A C^{+} A p o E^{-/-}$mice display increased cholesterol efflux-stimulating capacity. The $B A C^{+} A p o E^{-/-}$mice show dramatic reductions in atherosclerosis with only mild changes in lipid levels. This suggested that the protection against atherosclerosis may be mediated not only by changes in total lipid levels, but also influenced by changes in cellular function due to alterations in HDL composition. In support of this, various single nucleotide polymorphisms in humans may be associated with significant changes in susceptibility to atherosclerosis without obvious changes in total lipid levels (26). To determine whether serum and HDL isolated from $\mathrm{BAC}^{+}$transgenic mice show an altered capacity to act as an efflux acceptor, the cholesterol efflux-stimulating capacity of diluted serum isolated from these mice was measured in Fu5AH cells, a well-established and well-characterized system for measuring cholesterol efflux (25). Serum from the $B A C^{+} A p o E^{-/-}$mice was more effective in inducing cholesterol efflux as compared with serum from the $A p o E^{-/-}$mice $(18.32 \% \pm 0.32 \%$ vs. $16.75 \% \pm 0.08 \% ; P<0.0001$ ) (Table 2 ). To assess whether this greater efflux-stimulating capacity of serum was due to changes in the HDL fraction, the capacity of HDL (density between 1.063 and $1.210 \mathrm{~g} / \mathrm{ml}$ ) isolated from $B A C^{+} A p o E^{-/-}$mice and control littermates to induce efflux was compared. The HDL from $B A C^{+} A p o E^{-/-}$mice displayed a $33 \%$ higher capacity to induce efflux of cellular cholesterol than the HDL from control animals $(13.27 \% \pm 0.73 \%$ vs. $9.97 \% \pm 0.73 \% ; P=0.0007)$. It is notable that the relatively minimum effect observed with Fu5AH cells may be due to the fact that these cells rely mostly on SR-B1 for cholesterol efflux (27).

$H D L$ and lipid-free fractions from $A B C A 1 B A C^{+} A p o E^{-/-}$ mice show alterations in composition. The enhanced capacity of HDL from $B A C^{+} A p o E^{-/-}$mice to induce efflux suggested that these transgenic mice may show changes in HDL composition.

Interestingly, the chemical composition of HDL isolated by ultracentrifugation from plasma from the
$B A C^{+} A p o E^{-1-}$ mice show an increased phospholipid content $(P=0.05)$ (Table 3$)$. Linear regression analysis revealed a highly significant correlation between phospholipid content of HDL and its ability to induce efflux $\left(R^{2}=0.68, P=0.02\right)$ (Figure 4). A concurrent slight decrease in protein content was observed in the HDL from $B A C^{+} A p o E^{-/-}$mice (59\% vs. $64 \% ; P=0.04$ ). No significant difference in the cholesterol content of the HDL was observed ( $26 \%$ vs. $25 \%$; $P=0.42)$ (Table 3$)$. Triglyceride concentrations of the HDL were not detectable.

In addition, ApoA-I and ApoA-IV levels were measured in the lipid-free fractions with density greater than $1.21 \mathrm{~g} / \mathrm{ml}$. Since it has been shown that ultracentrifugation causes the loss of apolipoproteins from HDL fractions, we quantitated apolipoproteins from the lipid-free fraction. A $15 \%$ increase in ApoA-IV levels $(P=0.017)$ in the $B A C^{+} A p o E^{-/-}$mice compared with control littermates was evident (Table 4). There was no significant difference in the ApoA-I levels.

\section{Discussion}

A major, unanswered question has been whether raised ABCA1 levels can confer protection against atherosclerosis. In this study we have used the $A p o E^{-/-}$mice as a model for atherosclerosis and demonstrated that increased ABCA1 activity is associated with markedly reduced atherosclerosis. Not only was a decrease in lesion size evident, but also the increase in ABCA1 activity was associated with the appearance of earlier, less-complex lesions with no fibrous caps and less foam cell involvement.

An immediately relevant issue is how increased ABCA1 activity protects against atherosclerosis. Increases in $\mathrm{ABCA} 1$ levels in the $B A C^{+} A p o E^{-/-}$mice result in significantly increased efflux of cholesterol

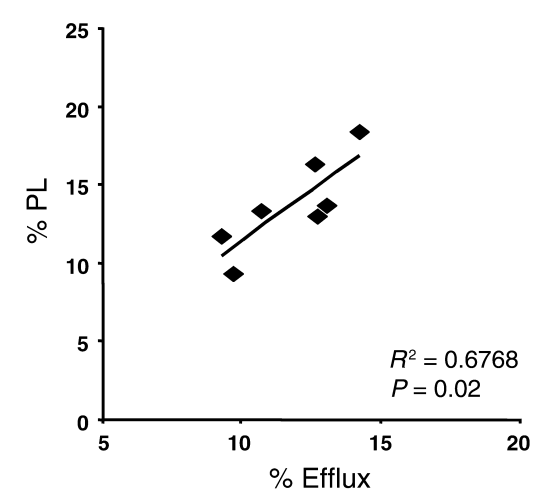

\section{Figure 4}

Correlation between the phospholipid content of HDL and its ability to elicit efflux. HDL (density between 1.063 and $1.21 \mathrm{~g} / \mathrm{ml}$ ) isolated from $B A C^{+} A p o E^{-/-}$and control $A p o E^{-/-}$mice was used for the quantification of phospholipid content and its ability to elicit cholesterol efflux. Phospholipid was quantified using a previously characterized method (21). Efflux was measured using Fu5AH cells, using protocols previously described (25). Linear regression analysis was performed on the percentage of phospholipid content of the HDL and the percentage of efflux elicited. The phospholipid content of HDL accounts for $68 \%$ of its ability to induce cholesterol efflux. PL, phospholipid. 
Table 3

HDL composition in $\mathrm{ABCA} 1 \mathrm{BAC}^{+} A p o E^{-/-}$and $A p o E^{-/-}$mice

\begin{tabular}{lccc}
\hline & \% Protein & \% Phospholipid & \% Cholesterol \\
$A p o E^{-/-}$ & $63.61 \pm 2.74$ & $11.44 \pm 1.99$ & $24.95 \pm 0.97$ \\
$B A C^{+} A p o E^{-/-}$ & $59.01 \pm 2.22$ & $15.33 \pm 2.49$ & $25.67 \pm 1.34$ \\
$P$ value & 0.04 & 0.05 & 0.42 \\
\hline
\end{tabular}

from peritoneal macrophages. However, on the $A p o E^{-/-}$ genetic background, this increase in efflux is accompanied only by a small increase in plasma HDL-C levels. Interestingly, $\mathrm{HDL}$ isolated from the $\mathrm{ABCA} 1 \mathrm{BAC}^{+}$ transgenic mice was significantly more capable of inducing efflux from cells, suggesting that qualitative as well as quantitative changes in HDL might contribute to its antiatherogenic activity.

Interestingly, $\mathrm{HDL}$ isolated from the $B A C^{+} A p o E^{-/-}$ mice contained significantly elevated phospholipid levels. ABCA1 has been proposed to be a phospholipid translocase/flippase $(9,11)$, and one suggested mechanism of induction of efflux by ABCA1 is that it directly (28) or indirectly (29) forms a complex with ApoA-I, thereby causing the translocation of phospholipids to ApoA-I and leading to the formation of phospholipidrich nascent HDL particles $(30,31)$, which can then promote cholesterol efflux from macrophages and other tissues $(32,33)$. Phospholipids are required for the formation of complexes between ApoA-I and cholesterol (34). Therefore, ABCA1-mediated translocation of phospholipids to ApoA-I generates nascent HDL particles that are primed for further cholesterol efflux. Evidence, in particular, for this process is that in our mice, phospholipid content of the HDL was associated with $68 \%$ of the variation in efflux. The mechanism by which ABCA1 stimulates efflux is therefore both direct by translocating phospholipids and cholesterol to nascent HDL particles and indirect through changing the phospholipid content of HDL itself, further stimulating cholesterol efflux. The phospholipid content of HDL has a strong linear association with cholesterol efflux (35). Small changes in HDL composition are associated with large changes in total cholesterol levels (36). For example, HDL-phospholipid is decreased in patients with coronary artery disease (CAD), and this is significantly correlated with increased severity of CAD (36).

Although there was no difference in ApoA-I and ApoAII content in the HDL from both groups of mice, a significant $15 \%$ increase in ApoA-IV levels in $B A C^{+} A p o E^{-/-}$ lipid-free Apo fraction was evident. One of the functions of ApoA-IV determined in vitro is to promote cholesterol efflux from extrahepatic cells, partly because it is a potent activator of lecithin:cholesterol acyltransferase (37). It also serves as a ligand for HDL binding to hepatocytes (38). Raised ApoA-IV levels also offer protection against atherosclerosis. One mechanism that has been proposed is that ApoA-IV is a surrogate for ApoA-I-containing particles in promoting reverse cholesterol transport (37) and may protect against atherosclerosis by mechanisms that are not directly related to HDL levels (39). ApoA-IV is a potent inhibitor of lipid oxidation, and oxidized LDL has an important role in the development of atherosclerosis. LDL oxidation is a prerequisite for its uptake by macrophages and the cellular accumulation of cholesterol (39). Thus, the elevated ApoA-IV levels that we observed in the $B A C^{+} A P O E^{-/-}$mice could itself confer additional protection against atherosclerosis. Taken together, our data suggest that ABCA1 plays a vital role in vivo, raising HDL levels and changing the composition of HDL, which facilitates the efflux of cholesterol from macrophages, leading in turn to a reduction in atherosclerotic lesions.

Joyce et al. (40) have addressed previously the role of $A B C A 1$ in atherosclerosis by generating $A B C A 1$ cDNA transgenic mice crossed with $A p o E^{-/-}$mice. Surprisingly, in contrast to our results, they showed 2- to 2.6-fold increase in the size of lesions in these $A B C A 1 \times A p o E^{-1-}$ mice. The major difference between our two studies is that Joyce et al. overexpressed the $A B C A 1 \mathrm{cDNA}$ using the $A p o E$ promoter containing its macrophage and hepatic control elements. In our study, on the other hand, ABCA1 was overexpressed using a construct containing endogenous regulatory elements $(17,41)$ to ensure that ABCA1 was expressed in a physiological manner in the proper cellular milieu and in response to the appropriate cell signals. $A B C A 1$ has sterol-responsive elements in its promoter region (42). These facts would argue that correct regulation in the appropriate cells is vital for the protective activity of ABCA1.

Using the ApoE promoter may to lead to nonphysiological cellular and subcellular expression of ABCA1. Indeed, in the article by Joyce et al. (40) there were only minimal nonsignificant changes in lipoproteins in the $b A B C A 1 \times A p o E^{-/-}$animals, with no reported changes in efflux, suggesting that exquisite physiological regulation of $A B C A 1$ by its natural promoter is essential for its normal function. These studies also suggest that ApoE and ABCA1 normally function in different subcellular compartments and confirm previously reported findings that ABCA 1 is not normally dependant on ApoE for promoting efflux (43). In our animals, ABCA1 clearly promotes efflux in the absence of ApoE. Our study also shows that even though ApoE can function similarly to ApoA-I as an acceptor for ABCA1-mediated efflux (44), the absence of ApoE as an acceptor is not rate limiting for the promotion of efflux and protection against atherosclerosis. The comparison between our two studies highlights the importance of using endogenous physiological promoters when addressing the role of a protein in a particular

\section{Table 4}

ApoA I and ApoA IV levels in the lipid free fraction isolated from $B A C^{+} A p o E^{-/-}$and $A p o E^{-/-}$mice

\begin{tabular}{lccc} 
& $A p o E^{-/-}$ & $B A C^{+} A p o E^{-/-}$ & $P$ value \\
ApoA I & $100 \pm 33$ & $104 \pm 40$ & NS \\
ApoA IV & $100 \pm 24$ & $115 \pm 23$ & 0.017 \\
\hline
\end{tabular}


process, in this case, atherosclerosis. Also, a recent report by Aiello et al. (45) indicates that when ABCA1 is inactivated in macrophages in the $A p o E^{-/-}$background, there is markedly increased atherosclerosis and foam cell accumulation, providing further confirmation for the modulation of atherosclerosis as predicted by changes in ABCA1 expression (15-17). In conclusion, our study demonstrates that raised $A B C A 1$ activity results in a significant reduction in atherosclerotic lesion size and complexity, likely due to increased efflux and consequent changes in HDL-C levels and HDL composition.

\section{Acknowledgments}

We are grateful to Darcy Davis, Catherine Lasselin, and members of the animal unit for excellent technical assistance, and the members of our respective groups for their intellectual input. This work was supported by the Canadian Institutes of Health Research (grant 20R91253 to M.R. Hayden), the Heart and Stoke Foundation of Canada (grant 20R53911 to M.R. Hayden), the Canadian Networks of Centers of Excellence (NCE Genetics, M.R. Hayden), and Xenon Genetics Inc. (M.R. Hayden). M.R. Hayden is a holder of a Canada Research Chair.

1. Gordon, D.J., et al. 1989. High-density lipoprotein cholesterol and cardiovascular disease - four prospective American studies. Circulation. 79:8-15

2. Fielding, C.J., and Fielding, P.E. 1997. Intracellular cholesterol transport. J. Lipid. Res. 38:1503-1521.

3. Mackness, M.I., Abbott, C., Arrol, S., and Durrington, P.N. 1993. The role of high-density lipoprotein and lipid-soluble antioxidant vitamins in inhibiting low-density lipoprotein oxidation. Biochem. J. 294:829-834.

4. Cockerill, G.W., Rye, K.A., Gamble, J.R., Vadas, M.A., and Barter, P.J. 1995. High-density lipoproteins inhibit cytokine-induced expression of endothelial cell adhesion molecules. Arterioscler. Thromb. Vasc. Biol. 15:1987-1994.

5. Stary, H.C., et al. 1994. A definition of initial, fatty streak and intermediate lesions of atherosclerosis. A report from the Committee on Vascular Lesions of the Council on Arteriosclerosis, American Heart Association. Arterioscler. Thromb. 14:840-856.

6. Tabas, I. 2000. Cholesterol and phospholipid metabolism in macrophages. Biochim. Biophys. Acta. 1529:164-174.

7. Fielding, C.J., and Fielding, P.E. 1995. Molecular physiology of reverse cholesterol transport. J. Lipid. Res. 36:211-228.

8. Rothblat, G.H., et al. 1999. Cell cholesterol efflux: integration of old and new observations provides new insights. J. Lipid. Res. 40:781-796.

9. Hamon, Y., et al. 2000. ABC1 promotes engulfment of apoptotic cells and transbilayer redistribution of phosphatidylserine. Nat. Cell Biol. 2:399-406.

10. Wang, N., Silver, D.L., Thiele, C., and Tall, A.R. 2001. ATP-binding cassette transporter A1 (ABCA1) functions as a cholesterol efflux regulatory protein. J. Biol. Chem. 276:23742-23747.

11. Wang, N., Silver, D.L., Costet, P., and Tall, A.R. 2000. Specific binding of ApoAI, enhanced cholesterol efflux, and altered plasma membrane morphology in cells expressing ABC1. J. Biol. Chem. 275:33053-33058.

12. Oram, J.F., Lawn, R.M., Garvin, M.R., and Wade, D.P. 2000. ABCA1 is the cAMP-inducible apolipoprotein receptor that mediates cholesterol secretion from macrophages. J. Biol. Chem. 275:34508-34511.

13. Assmann, G., von Eckardstein, A., and Brewer, Jr., H.B. 1995. Familial high density lipoprotein deficiency: Tangier disease. In The metabolic and molecular bases of inherited disease. C.R. Scriver, A.L. Beaudet, W.S. Sly, and D. Valle, editors. McGraw Hill Inc., New York, New York, USA. 2053-2072.

14. Marcil, M., et al. 1999. Mutations in the ABC1 gene in familial HDL deficiency with defective cholesterol efflux. Lancet. 354:1341-1346.

15. Clee, S.M., et al. 2000. Age and residual cholesterol efflux affect HDL cholesterol levels and coronary artery disease in ABCA1 heterozygotes. J. Clin. Invest. 106:1263-1270.

16. van Dam, M.J., et al. 2002. Association between increased arterial-wall thickness and impairment in ABCA1-driven cholesterol efflux: an observational study. Lancet. 359:37-42.

17. Singaraja, R.R., et al. 2001. Human ABCA1 BAC transgenic mice show increased high density lipoprotein cholesterol and ApoAI-dependent efflux stimulated by an internal promoter containing liver $\mathrm{X}$ receptor response elements in intron 1. J. Biol. Chem. 276:33969-33979.

18. Clee, S.M., et al. 2000. Plasma and vessel wall lipoprotein lipase have dif- ferent roles in atherosclerosis. J. Lipid. Res. 41:521-531.

19. Wellington, C.L., et al. 2002. ABCA1 mRNA and protein distribution patterns predict multiple different roles and levels of regulation. Lab Invest. 82:273-283

20. Bocan, T.M., et al. 2001. The combined effect of inhibiting both ACAT and HMG-CoA reductase may directly induce atherosclerotic lesion regression. Atherosclerosis. 157:97-105.

21. Peters, J.M., et al. 1997. Alterations in lipoprotein metabolism in peroxisome proliferator-activated receptor alpha-deficient mice. J. Biol. Chem. 272:27307-27312

22. Havel, R.J., Eder, H.A., and Bragdon, J.H. 1955. The distribution and chemical composition of ultracentrifugally separated lipoproteins in human serum. J. Clin. Invest. 34:1345-1353.

23. Lowry, O.J., Rosebrough, N.J., Farr, A.L., and Randall, R.J. 1951. Protein measurement with the Folin phenol reagent. J. Biol. Chem. 193:265-275.

24. Tailleux, A., et al. 2000. Decreased susceptibility to diet-induced atherosclerosis in human apolipoprotein A-II transgenic mice. Arterioscler. Thromb. Vasc. Biol. 20:2453-2458.

25. de la Llera Moya, M., et al. 1994. A cell culture system for screening human serum for ability to promote cellular cholesterol efflux. Relations between serum components and efflux, esterification, and transfer. Arterioscler. Thromb. 14:1056-1065.

26. Zwarts, K., et al. 2002. ABCA1 regulatory variants influence coronary artery disease independent of effects on plasma lipid levels. Clin. Genet. 61:115-125

27. Ji, Y., et al. 1997. Scavenger receptor BI promotes high density lipoproteinmediated cellular cholesterol efflux. J. Biol. Chem. 272:20982-20985.

28. Wang, N., Silver, D.L., Thiele, C., and Tall, A.R. 2001. ATP-binding cassette transporter $\mathrm{A} 1$ (ABCA1) functions as a cholesterol efflux regulatory protein. J. Biol. Chem. 276:23742-23747.

29. Chambenoit, O., et al. 2001. Specific docking of apolipoprotein A-I at the cell surface requires a functional ABCA1 transporter. J. Biol. Chem. 276:9955-9960

30. Hamilton, R.L., Williams, M.C., Fielding, C.J., and Havel, R.J. 1976. Discoidal bilayer structure of nascent high density lipoproteins from perfused rat liver. J. Clin. Invest. 58:667-680.

31. Winkler, K.E., and Marsh, J.B. 1989. Characterization of nascent high density lipoprotein subfractions from perfusates of rat liver. J. Lipid Res. 30:979-987.

32. Leventhal, A.R., Chen, W., Tall, A.R., and Tabas, I. 2001. Acid sphingomyelinase-deficient macrophages have defective cholesterol trafficking and efflux. J. Biol. Chem. 276:44976-44983.

33. Chen, W., et al. 2001. Preferential ATP-binding cassette transporter A1mediated cholesterol efflux from late endosomes/lysosomes. J. Biol. Chem. 276:43564-43569.

34. Vaughan, D.J., Breckenridge, W.C., and Stanacev, N.Z. 1980. Reconstitution of lipoproteins. I. Lipid-protein interaction of high density apoproteins, purified apoA-I and apoA-II with dimyristoyl-lecithin and dimyristoyllecithin:cholesterol vesicles studied by isomeric spin-labeled lecithins. Can. J. Biochem. 58:581-591.

35. Fournier, N., et al. 1996. Role of HDL phospholipid in efflux of cell cholesterol to whole serum: studies with human apoA-I transgenic mice. 1996 J. Lipid Res. 37:1704-1711.

36. Fournier, N., et al. 1997. HDL phospholipid content and composition as a major factor determining cholesterol efflux capacity from Fu5AH cells to human serum. Arterioscler. Thromb. Vasc. Biol. 17:2685-2691.

37. Fournier, N., et al. 2000. Human ApoA-IV overexpression in transgenic mice induces cAMP-stimulated cholesterol efflux from $\mathrm{J} 774$ macrophages to whole serum. Arterioscler. Thromb. Vasc. Biol. 20:1283-1292.

38. Nazih, H., et al. 2001. Butyrate stimulates ApoA-IV-containing lipoprotein secretion in differentiated Caco-2 cells: role in cholesterol efflux. J. Cell Biochem. 83:230-238.

39. Ostos, M.A., et al. 2001. Antioxidative and antiatherosclerotic effects of human apolipoprotein A-IV in apolipoprotein E-deficient mice. Arterioscler Thromb. Vasc. Biol. 21:1023-1028.

40. Joyce, C.W., et al. 2002. The ATP binding cassette transporter A1 (ABCA1) modulates the development of aortic atherosclerosis in C57BL/6 and ApoE-knockout mice. Proc. Natl. Acad. Sci. USA. 99:407-412.

41. Cavalier, L.B., et al. 2001. Regulation and activity of the human ABCA1 gene in transgenic mice. J. Biol. Chem. 276:18046-18051.

42. Costet, P., Luo, Y., Wang, N., and Tall, A.R. 2000. Sterol-dependent transactivation of the $\mathrm{ABC} 1$ promoter by the liver $\mathrm{X}$ receptor/retinoid $\mathrm{X}$ receptor. J. Biol. Chem. 275:28240-28245.

43. Huang, Z.H., Lin, C.Y., Oram, J.F., and Mazzone, T. 2001. Sterol efflux mediated by endogenous macrophage ApoE expression is independent of ABCA1. Arterioscler. Thromb. Vasc. Biol. 21:2019-2025.

44. Remaley, A.T., et al. 2001. Apolipoprotein specificity for lipid efflux by the human ABCAI transporter. Biochem. Biophys. Res. Commun. 280:818-823.

45. Aiello, R.J., et al. 2002. Increased atherosclerosis in hyperlipidemic mice with inactivation of ABCA1 in macrophages. Arterioscler. Thromb. Vasc. Biol. 22:630-637. 